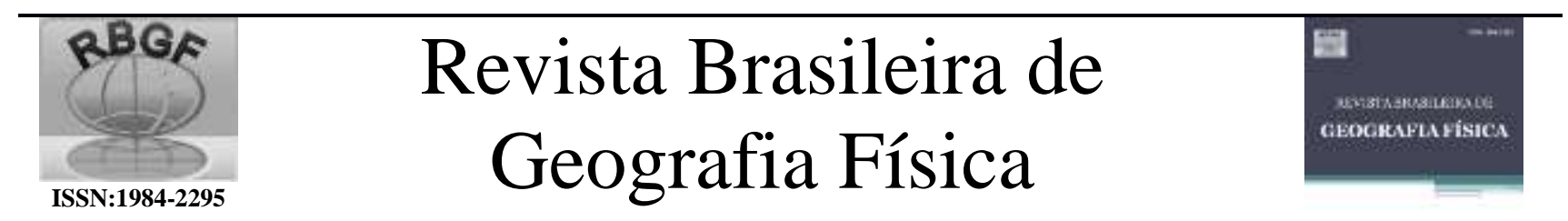

Homepage: www.ufpe.br/rbgfe

\title{
Climatologia urbana da cidade de Belém-Pará, através das precipitações e temperaturas do ar, das normais climatológicas de 1941 a 1970, 1971 a 2000 e da normal provisória de 2001 a 2015
}

\author{
Maria do Carmo Felipe de Oliveira ${ }^{1}$, José Augusto de Souza Júnior ${ }^{2}$, Patrícia Porta Nova da Cruz ${ }^{3}$, José \\ Danilo Souza Filho ${ }^{4}$.
}

\begin{abstract}
${ }^{1}$ Mestre - Universidade Federal do Pará - oliveiramaca@gmail.com - Autor Correspondente. ${ }^{2}$ Doutorando - Instituto Nacional de Pesquisas Espaciais - jun086@gmail.com, ${ }^{3}$ Doutora - Embrapa - Campinas - SP pportanova@gmail.com, ${ }^{4}$ Doutorando - Universidade Federal do Pará - danilosfilho@yahoo.com.br
\end{abstract}

Artigo recebido em 29/04/2016 e aceito em 27/06/2016.

\begin{abstract}
R E S U M O
Este trabalho teve como objetivo estudar a climatologia urbana de Belém-PA, tendo como base as precipitações e as temperaturas do ar, através da comparação entre as Normais Climatológicas de 1941-1970, 1971-2000 e a Normal Provisória de 2001-2015, buscando quantificar possíveis alterações climáticas e identificar a influência de eventos climáticos, de EL Niño e LA Niña, o que certamente contribuirá para um melhor planejamento urbano, visando na melhoria de qualidade de vida do homem. Foram utilizados os dados das precipitações e temperaturas do ar, fornecidos pelo Instituto Nacional de Meteorologia- INMET, e foram calculados parâmetros estatísticos e as anomalias anuais para identificar a variabilidade nos dados e a influência dos eventos extremos. Os resultados mostraram que, o regime médio mensal da precipitação pluviométrica e das temperaturas do ar, para as Normais, apresenta dois períodos distintos, um mais chuvoso e menos quente, de Janeiro a Maio e um menos chuvoso e mais quente, de Junho a Dezembro. Os totais médios mensais e anuais mostraram aumentos nas chuvas e nos valores de temperaturas do ar, quando comparados entre as Normais, porém, com alternância entre períodos de aumento gradual, com sequiência de queda. As anomalias mostraram a influência dos eventos climáticos extremos, na climatologia da região, tanto no regime pluviométrico, quanto no regime térmico, com redução e/ou aumento nos valores calculados, provocando secas severas e temperaturas mais elevadas, em anos de EL Niño e gerando grandes enchentes com transbordamento de rios e redução nos valores das temperaturas do ar em anos da La Niña.

Palavras - chave: Precipitações; Temperaturas do ar; Normais Climatológicas e Provisórias; Eventos Climáticos Extremos; Belém-PA.
\end{abstract}

\section{Urban climatology of the city of Belém-Pará-Brazil, throughout precipitation and air temperatures of climatology standards of 1941 to 1970,1971 to 2000 and provisional standard of 2001 to 2015}

\begin{abstract}
A B S T R A C T
This work aimed to study the urban climatology of Belém-Pará-Brazil, based on precipitation and air temperatures, by comparing the Climatological Standards of 1941-1970, 1971-2000 and provisional standard of 2001-2015, seeking quantify potential climate change and identify the influence of weather events, like El Niño and La Niña events, which will certainly contribute to a better urban planning in order to improve man's quality of life. Precipitation and air temperatures data were used in the research, provided by the National Institute of Meteorology (INMET), and were calculated statistical parameters and annual anomalies to identify the variability in the data and the influence of extreme events. The results showed that the monthly average pattern of rainfall and air temperatures, for the Climatological Standards, demonstrate two distinct periods, one rainier and less hot, from January to May and a less rainy and warmer, from June to December. Annual and monthly average totals demonstrated increases in rainfall and in air temperature values, when compared between the Standards, however, with alternating periods of gradual increase, with decrease sequence. Anomalies showed the influence of extreme weather events, in the climatology of the region, both in rainfall as thermal patterns, with reduction and/or increase in the calculated values, causing severe drought and higher air
\end{abstract}

Oliveira, M.C.F.; Souza Júnior, J.A.; Cruz, P.P.N.; Souza Filho, J.D. 
temperatures in years of El Niño and causing large floods with overflowing in rivers and reduced values of air temperatures in the La Niña years.

Keywords: Precipitation; Air temperature; Climatological Standard and provisional; Extreme climate events; BelémPará-Brazil.

\section{Introdução}

A cidade de Belém localiza-se as margens da Baia do Guajará e Rio Guamá, no estuário do Rio Pará, em Zona Tropical, apresenta clima quente e elevado índice pluviométrico durante todo o ano. As variáveis meteorológicas, estando relacionadas com fenômenos de escala global, são influenciadas por vários processos de grande escala, mesoescala e microescala. Como evento de grande escala, destaca-se a Zona de Convergência Intertropical (ZCIT), responsável pela chuva que cai na região nos meses mais chuvosos, e por eventos climáticos extremos, como os fenômenos de EL Niño e LA Niña; como evento de mesoescala as linhas de Instabilidade, formadas no nordeste do Pará e que entram pela região, responsável pelas chuvas nos meses mais secos (Cohen, 1989); e por evento de microescala, os efeitos locais, como aquecimento da superfície, que provocam a formação de nuvens na região. Considerando a importância da precipitação que exerce influência direta sobre as condições ambientais, agindo diretamente sobre o balanço de água no solo e indiretamente através de outros elementos como temperatura e umidade do ar e do solo e radiação solar, existe grande esforço no sentido de previsões de sua ocorrência e da sua variação espacial, que são de interesse prático em estudos específicos, como conforto humano e estudos gerais do clima.

Este trabalho teve como objetivo, estudar o clima urbano de Belém-Pa, usando como elementos meteorológicos a precipitação pluviométrica e as temperaturas do ar, fazendo a comparação entre as Normais Climatológicas de 1941- 1970 e 1971- 2000 (segundo a OMM, a Normal Climatológica é a média de uma série de dados climáticos de 30 anos) e a Normal Provisória de 2001-2015 (segundo a Organização Meteorológica Mundial, uma Normal Provisória representa as condições médias a partir dos últimos 10 anos) (Krusche \& Saraiva, 2001), buscando quantificar possíveis alterações climáticas nos valores das precipitações pluviométricas e das temperaturas do ar, bem como, analisar as anomalias relacionadas com as ocorrências dos eventos climáticos extremos de EL Niño e La Niña (em períodos de EL Niño a tendência é de redução das chuvas na região, enquanto que, com a atuação da La Niña, a tendência é de aumento nos valores da precipitação na região) (Souza Júnior, 2008), visando dar subsídios a população e as políticas públicas, com vista às melhorias nas condições ambientais, sociais e econômicas da região.

\section{Material e métodos}

A cidade de Belém-PA localiza-se as margens da Baia do Guajará e Rio Guamá, no estuário do Rio Pará a $1^{\circ} 28^{\prime}$ Sul de latitude, $48^{\circ} 29^{\prime}$ 'Oeste de longitude, com altitude média de 5 metros acima do nível do mar, Figura 01. Neste trabalho foram usados dados de precipitação pluviométrica e de temperatura do ar, obtidos no Instituto Nacional de Meteorologia - INMET, para Belém-Pa, das Normais Climatológicas de 1941-1970, 1971-2000, e da Normal Provisória de 2001-2015, e foram comparados entre si, para observar aumento ou redução de chuvas e nos valores das temperaturas do ar, na região. Foram calculados os valores totais médios mensais e anuais e cálculos estatísticos como a média, desvio-padrão e coeficiente de variação, onde o desvio-padrão e o coeficiente de variação medem a variabilidade das séries analisadas, a fim de comparar com o padrão climatológico, das Normais estudadas. Com base nas médias aritméticas, foram calculadas as anomalias anuais $(\mathrm{Xi}-\mathrm{X})$, onde $\mathrm{Xi}$ é a variável e $\mathrm{X}$ é a média da Normal Climatológica, para mostrar o quanto, cada ano se afasta do valor médio (da média climatológica) e esses afastamentos, podem ser negativos (períodos secos) ou positivos (período mais chuvoso). Com os valores obtidos, foram elaboradas figuras e quadros, a fim de verificar possíveis alterações e ou modificações, nos valores encontrados, sempre em comparação entre as Normais Climatológicas e a Normal Provisória e através dos cálculos das anomalias serão então identificados os anos de ocorrência de EL Niño e 
La Niña, definindo assim, a variabilidade dos elementos meteorológicos em estudo, na região.

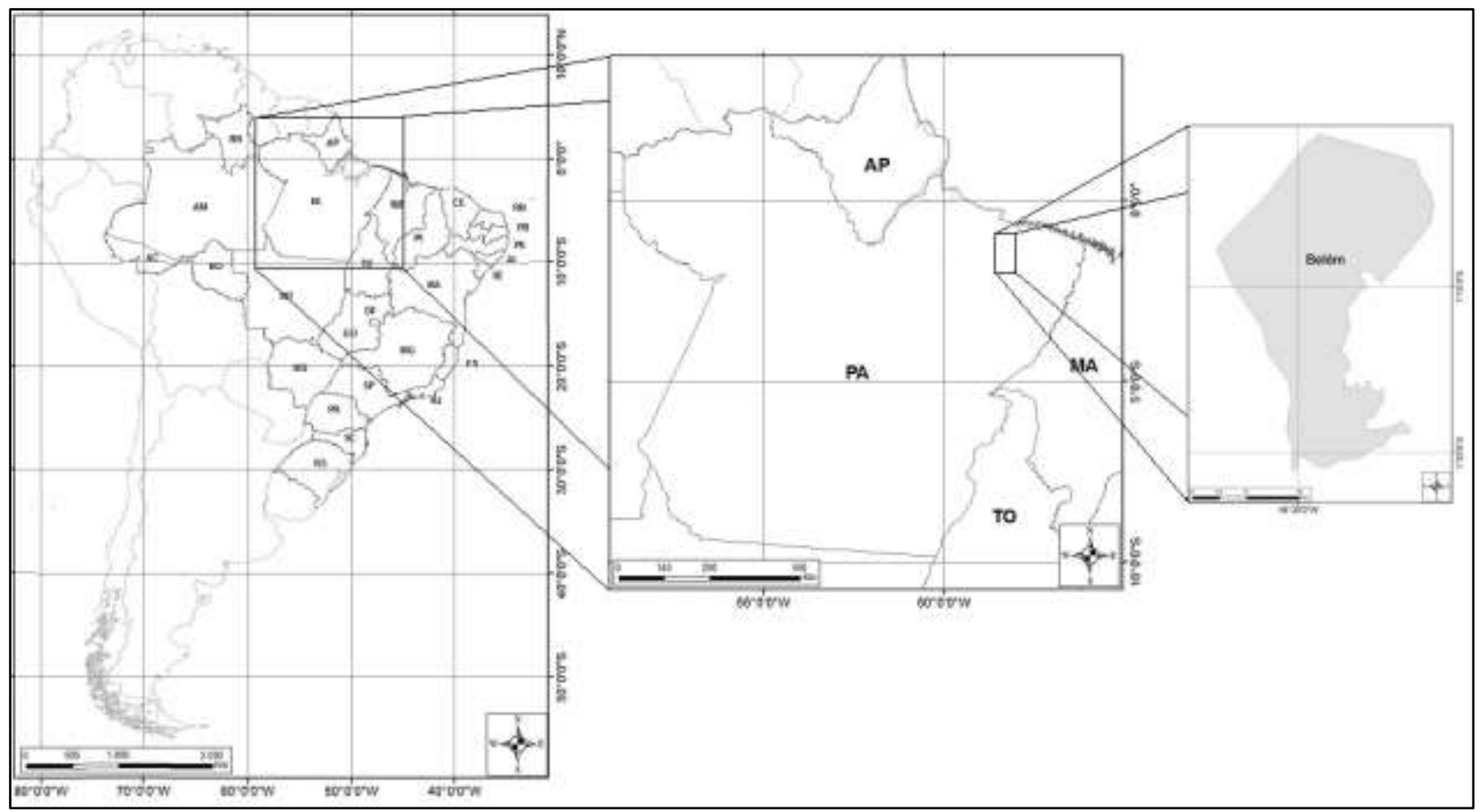

Figura 1 - Localização da Cidade Belém - PA

\section{Resultados e discussão}

Climatologia de Belém-Pa.

Precipitação pluviométrica:

Totais Médios Mensais das Precipitações Pluviométricas.

$\mathrm{O}$ total médio mensal do regime pluviométrico na cidade de Belém-Pa, durante os períodos estudados das Normais Climatológicas de 1941-1970, 1971-2000 e Normal Provisória de 2001-2015, Figura 02, apresenta um período chuvoso compreendido de janeiro a maio, ocorrendo maior concentração da precipitação no trimestre, fevereiro, março e abril, com $43,4 \%$ (1941-1970), com 42,9\% (1971-2000) e com 42,0\% (2001-2015) nos totais médios anuais de precipitação, e um período menos chuvoso, abrangendo os demais meses do ano, com menor concentração no trimestre, setembro, outubro e novembro, contribuindo com $11,7 \%$, com $11,1 \%$ e com $11,4 \%$, do total médio anual de precipitação, das respectivas Normais Climatológicas e Provisórias. Observa-se ainda, aumento da precipitação pluviométrica média mensal, quando comparamos as Normais Climatológicas e a Normal Provisória, apresentando uma elevação no total médio mensal da precipitação.

$\mathrm{Na}$ cidade de Belém-PA, as fortes chuvas que ocorrem na região, no período mais chuvoso, são influenciadas pela massa equatorial continental, que condiciona movimentos convectivos dos alísios de Nordeste e Sudeste, Zona de Convergência Intertropical - ZCIT e no período menos chuvoso a precipitação observada na região é devido, principalmente, aos efeitos locais, como aquecimento da superfície, que por sua vez provoca a formação de nuvens na região, fazendo de Belém-Pa, cidade tradicionalmente reconhecida como sujeita as chuvas abundantes. 


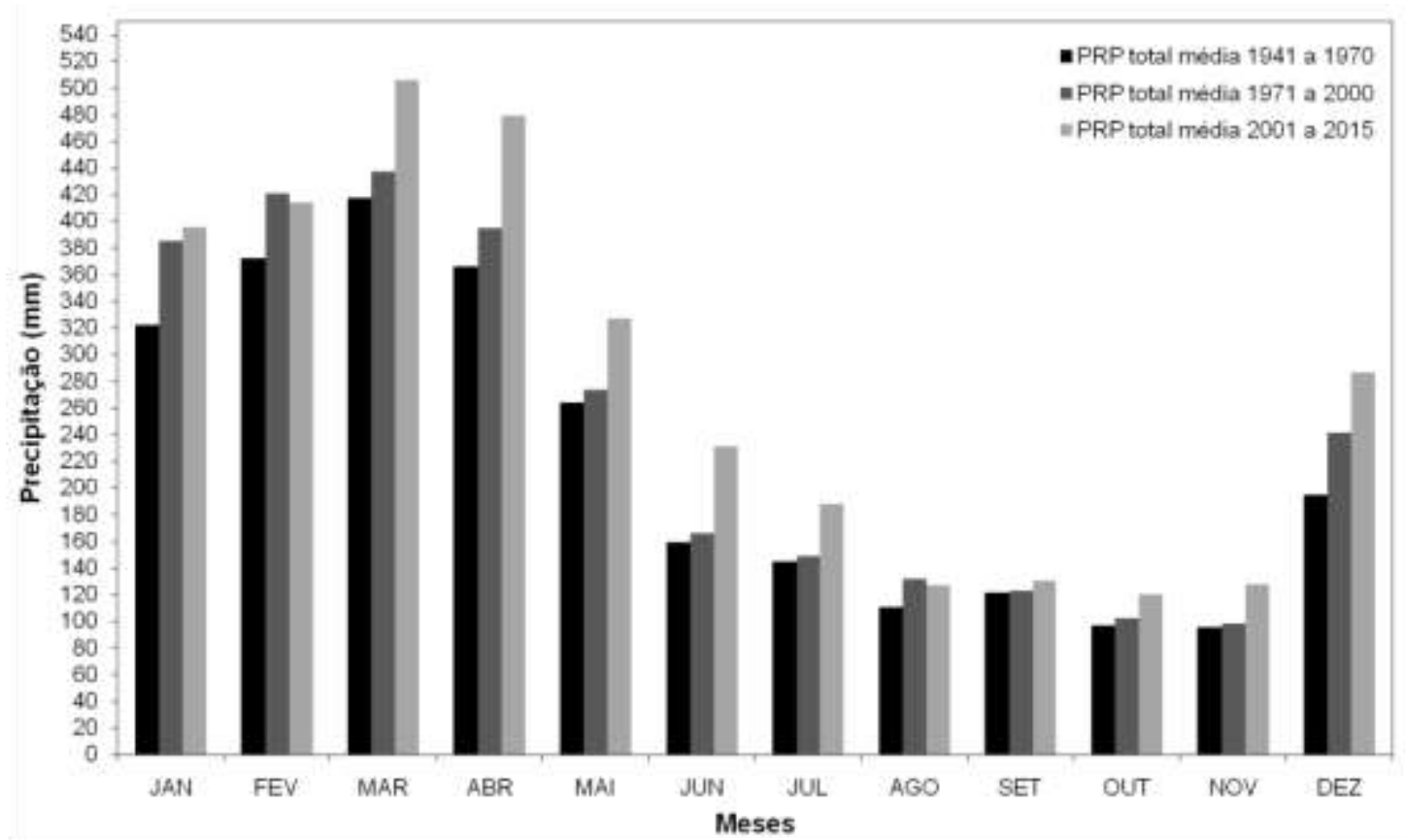

Figura 2- Regime Pluviométrico Médio Mensal das Normais Climatológicas, 1941-1970, 1971-2000 e Normal Provisória de 2001-2015, para Belém-PA.

Totais médios anuais das precipitações pluviométricas.

A Figura 03 mostra os totais anuais de precipitação pluviométrica para as Normais Climatológicas e Provisórias para Belém do Pará e observamos uma variabilidade interanual, caracterizada por um movimento cíclico ao longo do período, com uma tendência de aumento na precipitação pluviométrica, com total médio anual de $2661 \mathrm{~mm}$ para a Normal de 1941 a 1970, de $2925 \mathrm{~mm}$ para a Normal de 1971 a 2000 e $3333 \mathrm{~mm}$ para a Normal Provisória, e quando comparamos as normais, observamos uma elevação de $10 \%$ na Normal 1971-2000 e de $25 \%$ na Normal de 2001-2015 em relação a Normal de 1941-1970, bem como, um aumento de $14 \%$ na Normal Provisória em relação a Normal Climatológica de 1971 a 2000. Os cálculos estatísticos mostraram que, o desvio-padrão para cada uma das Normais, foi de $349 \mathrm{~mm}$, de $348 \mathrm{~mm}$ e de $289 \mathrm{~mm}$ e o coeficiente de variação foi de $13 \%, 12 \%$ e de $9 \%$, respectivamente, mostrando que ambas as Normais Climatológicas (30 anos) apresentaram maiores variabilidades, quando comparados aos valores das Normais Provisórias (15 anos). 


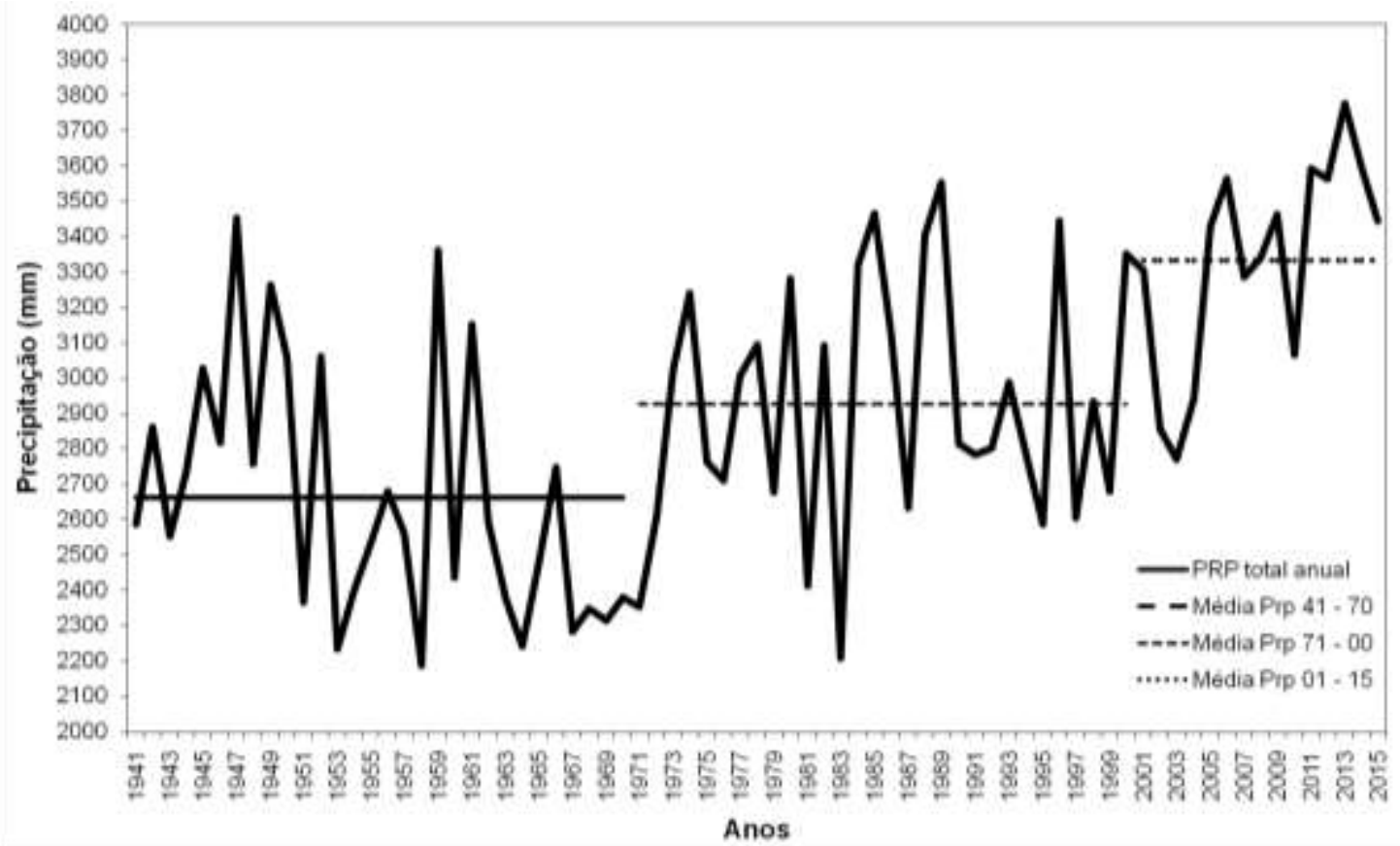

Figura 3 - Totais médios anuais de precipitação pluviométrica para as Normais Climatológicas, 1941-1970 e 1971-2000 e Normal Provisória, 2001-2015, para Belém-PA.

Valores totais médios mensais e anuais e valores extremos das precipitações, com os anos de ocorrências.

No Quadro 01, são mostrados os valores totais médios mensais e anuais e valores extremos mensais e anuais com os anos de ocorrências, da precipitação pluviométrica das Normais Climatológicas e Normal Provisória, para BelémPa, onde para o período da Normal de 1941-1970, o valor máximo mensal foi de $696 \mathrm{~mm}$ em março de 1947 e o valor mínimo mensal foi de $26 \mathrm{~mm}$, em outubro de 1969; para o período da Normal de 1971-2000, o valor máximo foi de $776 \mathrm{~mm} \mathrm{em}$ fevereiro de 1980 e valor mínimo de $8 \mathrm{~mm} \mathrm{em}$ outubro de 1997 e para o período de 2001-2015, o valor máximo foi de $743 \mathrm{~mm}$ em março de 2012 e valor mínimo de $26 \mathrm{~mm}$ em outubro de 2015 . Observa-se que, durante os anos de ocorrência do fenômeno El Niño, ocorre uma redução nos totais mensais de precipitação, como observado nos meses e nos anos menos chuvosos, nas Normais estudadas, como outubro de 1969, de 1997 e 2015, respectivamente, enquanto que, a ocorrência do fenômeno da La Niña, influenciou em alguns dos períodos, no aumento da precipitação total mensal, das Normais aqui estudadas, pois as maiores chuvas ocorreram em março de 1947 , fevereiro de 1980 e março de 2012, sendo alguns desses anos influenciados pela ocorrência do referido evento. No Quadro 01, observa-se também que, que o ano de 1947 foi o mais chuvoso com total anual de $3453 \mathrm{~mm}$ para a Normal de 1941-1970, o ano de 1989 com $3552 \mathrm{~mm}$ para a normal de 1971-2000 e o ano de 2013 com $3776 \mathrm{~mm}$ para a Normal Provisória de 2001-2015, e esses anos estavam sob efeito de evento forte da La Niña, enquanto que, os anos menos chuvosos foram 1958 com $2186 \mathrm{~mm}, 1983$ com 2208mm e o ano de 2003 com 2769mm, respectivamente, e estavam sob a influência de evento forte do El Niño, ou seja, em anos de El Niño, ocorre diminuição nos totais anuais de chuvas, trazendo como conseqüências secas e em contrapartida, em anos de La Niña, ocorrem elevações nos totais pluviométricos, gerando grandes enchentes com transbordamentos dos rios, na região de estudo. 
Quadro 1 - Valores totais médios anuais e valores extremos mensais e anuais das precipitações, com os anos de ocorrência, para as Normais Climatológicas e Provisórias, para Belém-PA.

\begin{tabular}{|c|c|c|c|}
\hline \multicolumn{4}{|c|}{ PRECIPITAÇ̃̃O $(\mathrm{mm})$} \\
\hline & $1941-1970$ & $1971-2000$ & $2001-2015$ \\
\hline Total Médio Mensal & 2661 & 2925 & 3333 \\
\hline Valor Máximo Mensal & 696 (março de 1947) & $776($ fevereirode1980) & 743 (março de 2012) \\
\hline Valor Mínimo Mensal & 26 (outubro 1969) & 8 (outubro de 1997) & 26 (outubro de 2015) \\
\hline Valor Máximo Anual & $3453(1947)$ & $3552(1989)$ & $3776(2013)$ \\
\hline Valor Mínimo Anual & $2186(1958)$ & $2208(1983)$ & $2769(2003)$ \\
\hline
\end{tabular}

Anomalias anuais das precipitações pluviométricas em relação às respectivas médias climatológicas.

A Figura 04 mostra os valores das anomalias (positivas e negativas) das precipitações anuais para cada uma das Normais em relação a sua respectiva média climatológica, e observa-se que, para a Normal de 1941-1970, o ano de 1947 a precipitação ultrapassou os 700 mm; para a Normal de 1971-2000, o ano 1989, ultrapassou os $600 \mathrm{~mm}$ e para a Normal 20012015, o ano 2013, ultrapassou os 400mm, em relação as médias climatológicas, tendo a La Niña influenciado nesses anos, apresentando excessos de chuvas na região, enquanto que, nos anos de El Niño ocorreu déficit de chuvas de $-400 \mathrm{~mm}$, no ano de 1958, de - $700 \mathrm{~mm}$ no ano de 1983 e de $500 \mathrm{~mm}$ no ano de 2003, respectivamente. Para os períodos de ocorrência do fenômeno La Niña, os anos de 1947, 1989 e 2013 (anos de forte evento) ocorreram os maiores excedentes de chuvas, com valores de $792 \mathrm{~mm}, 628 \mathrm{~mm}$ e $443 \mathrm{~mm}$ acima das médias climatológicas, respectivamente, e para os períodos de forte intensidade de ocorrência do fenômeno El Niño, os anos de 1958, 1983 e 2003, ocorreram os maiores déficit de chuvas, chegando a $-476 \mathrm{~mm},-717 \mathrm{~mm}$ e $-564 \mathrm{~mm}$, abaixo das médias climatológicas, respectivamente, logo, escassez de chuvas. Tais anomalias mostraram o quanto ocorreu de excedentes e de déficits de chuvas, em relação ao valor médio climatológico. Mas outros fatores de escalas globais, como ZCIT, linhas de instabilidade, e fatores locais e a expansão urbana desordenada, podem influenciar no aumento das chuvas na região. 


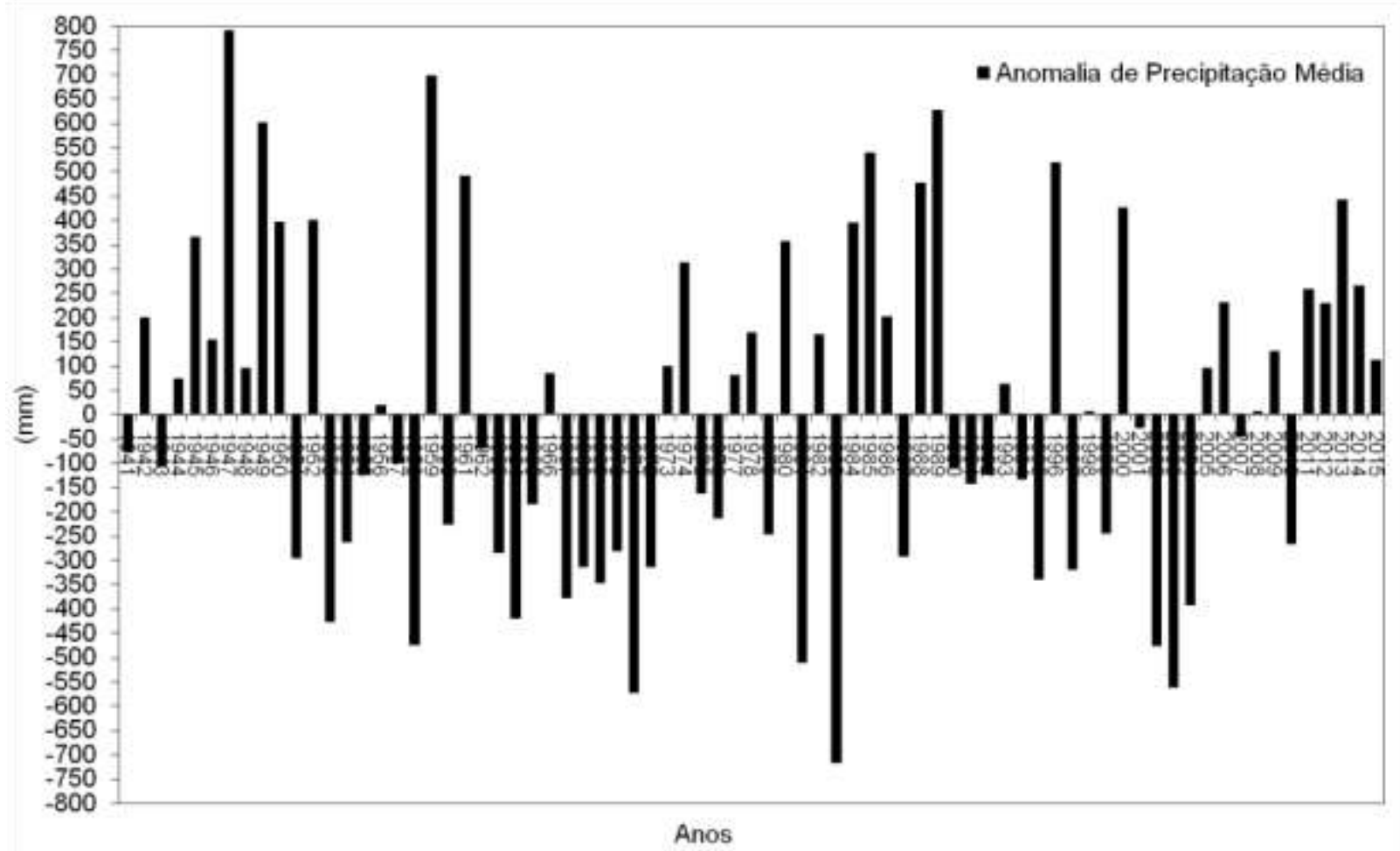

Figura 4 - Anomalias de precipitação pluviométrica anuais, em relação as Normais Climatológicas de 1941-1970, 19712000 e 2001-2015, para Belém-Pa.

Temperaturas do Ar.

Temperatura do ar média mensal, médias máximas e médias mínimas mensais:

As Figuras 05, 06 e 07 mostram as temperaturas do ar média mensal, das temperaturas médias, das médias máximas e médias mínimas, para as Normais Climatológicas e Normais Provisórias, para Belém-Pa e observase que, na Figura 04, durante o período mais chuvoso, janeiro a maio, as temperaturas médias mensais são menos elevadas, quando comparadas com o período menos chuvoso, de junho a dezembro, que, apresentam-se mais elevadas. $\mathrm{O}$ mês menos quente é março com temperaturas médias de $25,4{ }^{\circ} \mathrm{C}$ na Normal 1941-1970, de $25,5^{\circ} \mathrm{C}$ na Normal de $1971-2000$ e de $26,2^{\circ} \mathrm{C}$ na Normal Provisória de 2001-2015, enquanto que, o mês mais quente é novembro com $26,3^{\circ} \mathrm{C}, 26,7^{\circ} \mathrm{C}$ e $27,6^{\circ} \mathrm{C}$, respectivamente.

A Figura 05 mostra a temperatura do ar média máxima mensal, para as Normais Climatológicas e a Normal Provisória, para Belém-Pa e observa-se que, o mês menos quente é março com temperaturas médias máximas de $30,2^{\circ} \mathrm{C}$, de $30,5^{\circ} \mathrm{C}$ e de $31,3^{\circ} \mathrm{C}$, respectivamente, enquanto que, o mês mais quente é novembro com $32,3^{\circ} \mathrm{C}, 32,4^{\circ} \mathrm{C}$ e $33,4^{\circ} \mathrm{C}$, respectivamente.

A Figura 06 mostra a temperatura do ar média mínima mensal, para as Normais aqui estudadas, para Belém-Pa e observa-se que, o mês com temperaturas mais elevadas foi março com temperaturas médias mínimas de $23,0{ }^{\circ} \mathrm{C}$, de $22,9^{\circ} \mathrm{C}$ e de $23,4^{\circ} \mathrm{C}$, respectivamente, enquanto que, o mês de outubro apresenta menores temperaturas médias mínimas, com $21,9^{\circ} \mathrm{C}$, $22,2^{\circ} \mathrm{C}$ e $23,0^{\circ} \mathrm{C}$, respectivamente. As temperaturas médias mensais apresentaram pequenas elevações nos seus valores, quando comparamos as médias mensais, entre as Normais aqui estudadas. No comportamento médio mensal das temperaturas do ar, o regime térmico caracteriza a região como clima quente, com a presença de altas temperaturas, o que significa dizer que, essas elevações na temperatura do ar podem ser devido aos fatores locais, natureza do solo, nebulosidade e ventos calmos. 


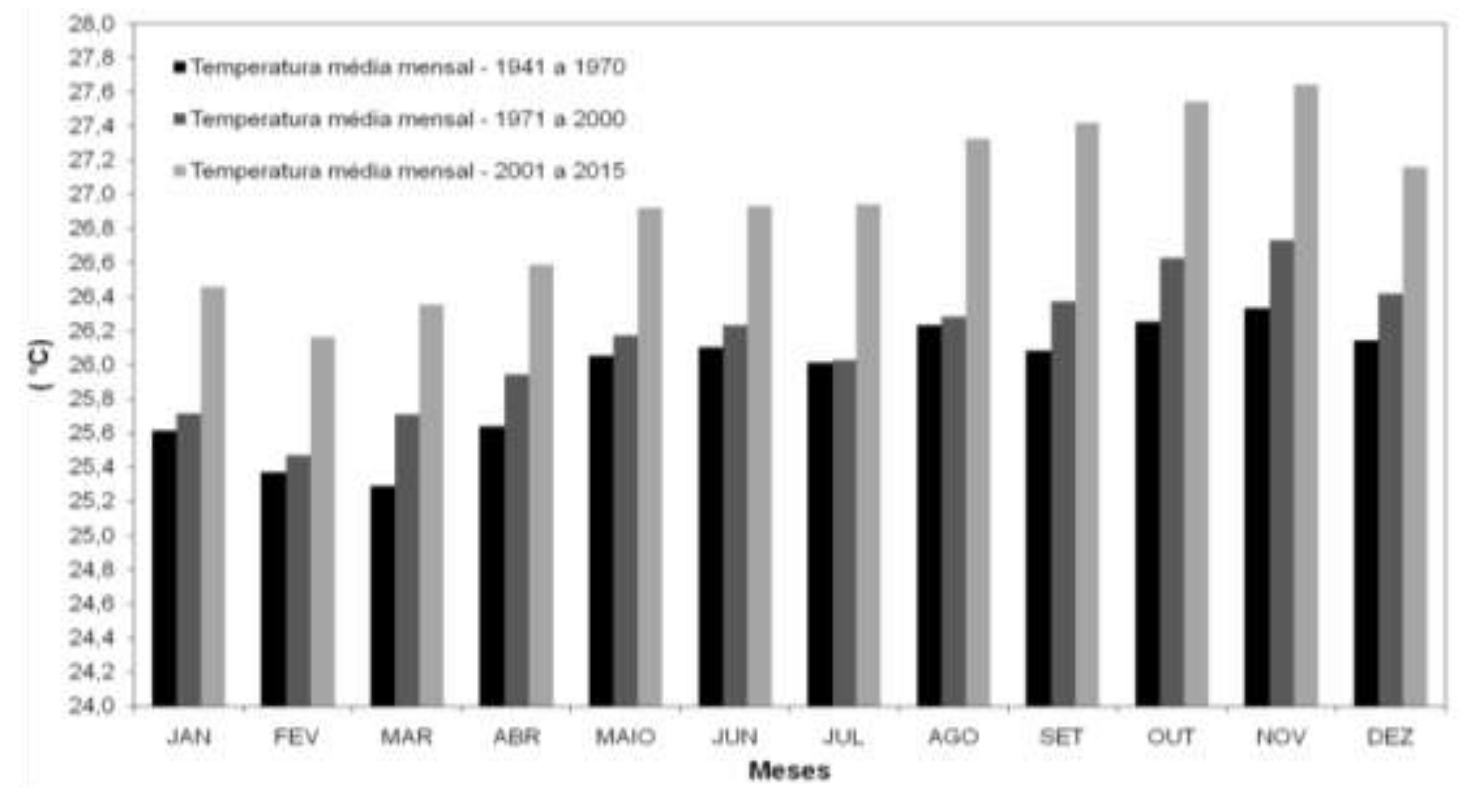

Figura 5 - Temperatura do Ar Médio Mensal das Normais Climatológicas, 1941-1970, 1971-2000 e Normal Provisória de 2001-2015, para Belém-PA.

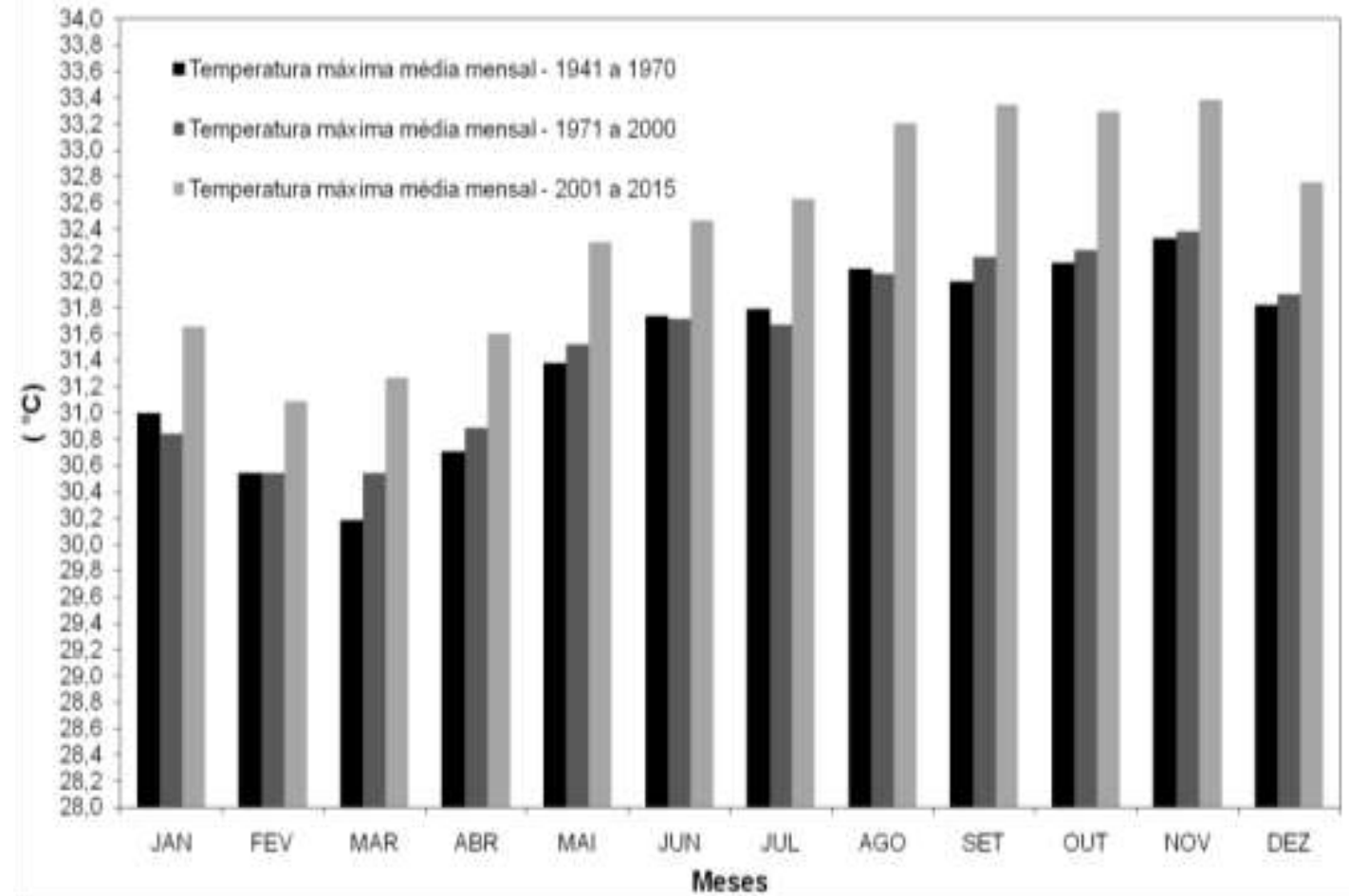

Figura 6 - Temperatura do Ar Média Máxima Mensal das Normais Climatológicas, 1941-1970, 1971-2000 e Normal Provisória de 2001-2015, para Belém-PA. 


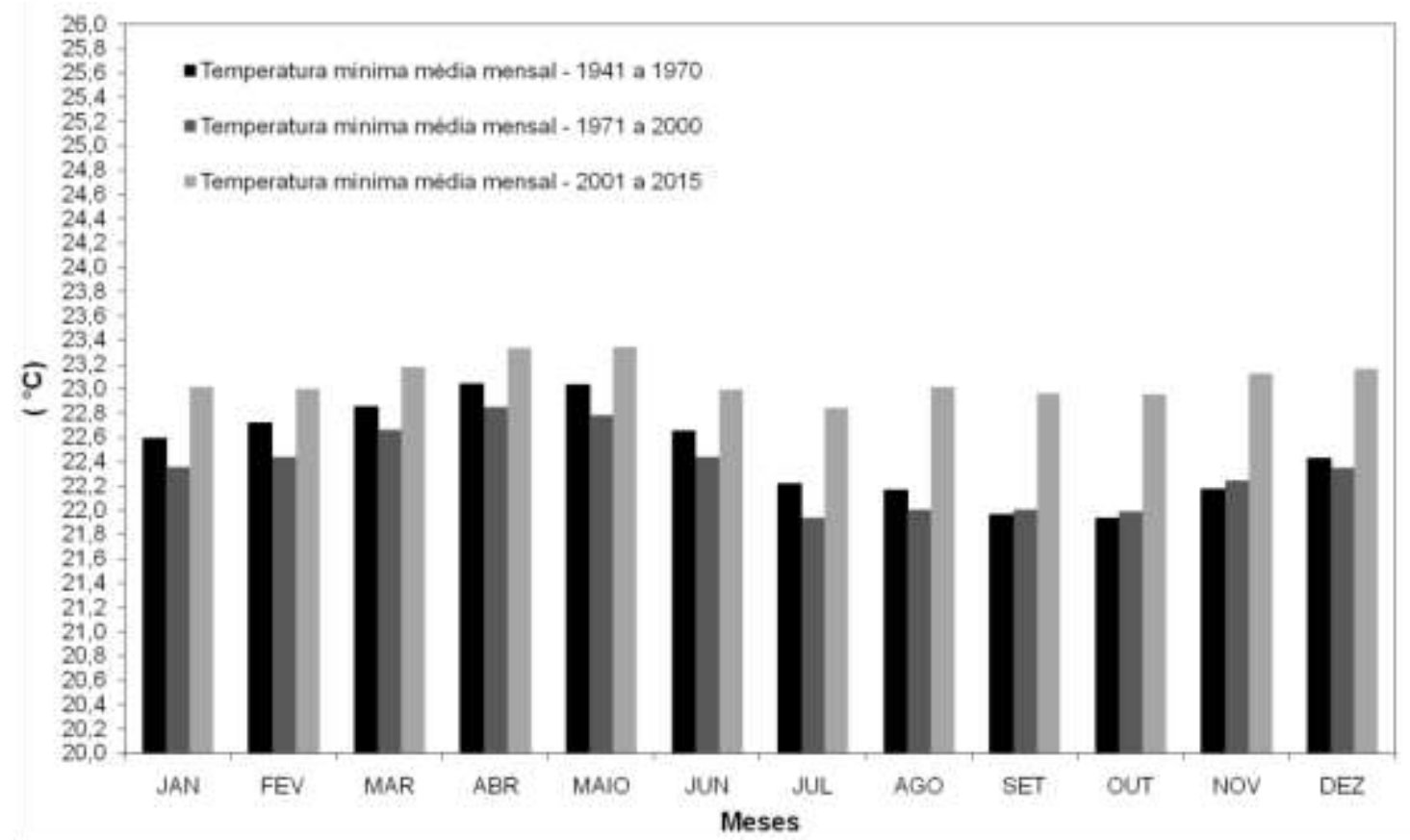

Figura 7 - Temperatura do Ar Média Mínima Mensal das Normais Climatológicas, 1941-1970, 1971-2000 e Normal Provisória de 2001-2015, para Belém-PA.

Valores extremos mensais de temperatura do ar, com os anos de ocorrência.

No Quadro 02, são mostrados os valores extremos mensais e os anos de ocorrências, das temperaturas do ar médias, médias máximas e médias mínimas das Normais Climatológicas e Normal Provisória, para Belém-Pa, onde os valores extremos de temperatura média do ar, para a normal de $1941-1970$ foi de $27,7^{\circ} \mathrm{C}$ em agosto de 1958 e de $24,4{ }^{\circ} \mathrm{C}$, em fevereiro de 1950 ; para o período da Normal de $1971-2000$, foi de $27,7^{\circ} \mathrm{C}$ em outubro de 1997 e de $24,3^{\circ} \mathrm{C}$ em fevereiro de 1975 e para o período da Normal Provisória de 2001-2015, os valores foram de $28,4^{\circ} \mathrm{C} \mathrm{em}$ outubro de 2015 e de $25,5^{\circ} \mathrm{C}$ em fevereiro de 2001e 2008; os valores máximos e mínimos das temperaturas médias máximas mensais foram de $34,6^{\circ} \mathrm{C}$ em outubro de 1969 e de $28,5^{\circ} \mathrm{C}$ em março de1947; de $33,7^{\circ} \mathrm{C}$ e de $28,6^{\circ} \mathrm{C}$ em outubro de 1996 e em fevereiro de 1980 ; e de $34,6^{\circ} \mathrm{C}$ em novembro de 2014 e de $29,8^{\circ} \mathrm{C}$ em janeiro de 2001; Os valores extremos das temperaturas médias mínimas mensais foram de $23,8^{\circ} \mathrm{C}$ em janeiro de1952 e de $20,5^{\circ} \mathrm{C}$ em outubro de 1967 ; de $24,5^{\circ} \mathrm{C}$ em abril de 1998 e de $20,1^{\circ} \mathrm{C}$ em fevereiro de 1977 ; e de $24,3^{\circ} \mathrm{C}$ e de $22,0^{\circ} \mathrm{C}$ em maio de 2011 e em janeiro de 2013 e 2015, respectivamente. Observa-se que em alguns anos de El Niño, ocorre uma elevação nas médias mensais, com valores acima das médias das normais climatológicas e em anos de La Niña, as temperaturas apresentam-se com valores abaixo das médias das normais, justificando que os fenômenos influenciam nas temperaturas médias do ar, médias, máximas e mínimas, nos períodos estudados, mas não podem ser desprezados outros fatores de escala global, pois a cidade de Belém$\mathrm{Pa}$, estando localizada na zona Tropical, possui clima quente, com regime térmico estável, com pequenas variações no decorrer dos meses, proporcionando uma maior incidência de radiação solar e conseqüentemente, um maior aumento nas temperaturas do ar. 
Quadro 2 - Valores Extremos Médios Mensais de Temperatura do Ar Média, Máxima e Mínima, com os anos de ocorrência, para as Normais Climatológicas e Provisórias, para Belém-PA.

\begin{tabular}{|c|c|c|c|}
\hline \multicolumn{4}{|c|}{ Temperatura Média do $\operatorname{Ar}\left({ }^{\circ} \mathrm{C}\right)$} \\
\hline & 1941-1970 & $1971-2000$ & 2001-2015 \\
\hline Média Mensal & 25,9 & 26,1 & 27,0 \\
\hline Valor Máximo Mensal & $\begin{array}{c}27,7 \text { (Agosto de } \\
1958 \text { ) }\end{array}$ & $\begin{array}{c}27,7 \text { (Outubro de } \\
\text { 1997) }\end{array}$ & $\begin{array}{c}28,4 \text { (Outubro de } \\
\text { 2015) }\end{array}$ \\
\hline Valor Mínimo Mensal & $\begin{array}{c}\text { 24,4 (Fevereiro de } \\
\text { 1950) }\end{array}$ & $\begin{array}{c}24,3 \text { (Fevereiro de } \\
1975)\end{array}$ & $\begin{array}{c}25,5 \text { (Fevereiro de } \\
2001 \text { e } 2008)\end{array}$ \\
\hline \multicolumn{4}{|c|}{ Temperatura Média Máxima $\left({ }^{\circ} \mathrm{C}\right)$} \\
\hline & $1941-1970$ & $1971-2000$ & $2001-2015$ \\
\hline Média Mensal & 31,5 & 31,5 & 32,4 \\
\hline Valor Máximo Mensal & $\begin{array}{c}\text { 34,6 (Outubro de } \\
1969 \text { ) }\end{array}$ & $\begin{array}{c}\text { 33,7 (Outubro de } \\
\text { 1996) }\end{array}$ & $\begin{array}{c}\text { 34,6 (Novembro de } \\
\text { 2014) }\end{array}$ \\
\hline Valor Mínimo Mensal & $\begin{array}{c}\text { 28,5 (Março de } \\
1947)\end{array}$ & $\begin{array}{c}28,6 \text { (Fevereiro de } \\
1980)\end{array}$ & $\begin{array}{l}\text { 29,8 (Janeiro de } \\
\text { 2001) }\end{array}$ \\
\hline \multicolumn{4}{|c|}{ Temperatura Média Mínima $\left({ }^{\circ} \mathrm{C}\right)$} \\
\hline & $1941-1970$ & $1971-2000$ & $2001-2015$ \\
\hline Média Mensal & 22,5 & 22,3 & 23,1 \\
\hline Valor Máximo Mensal & $\begin{array}{c}\text { 23,8 (Janeiro de } \\
\text { 1952) }\end{array}$ & $\begin{array}{c}\text { 24,5 (Abril de } \\
1998 \text { ) }\end{array}$ & 24,3 (Maio de 2011) \\
\hline Valor Mínimo Mensal & $\begin{array}{c}\text { 20,5 (Outubro de } \\
1967 \text { ) }\end{array}$ & $\begin{array}{c}\text { 20,1 (Fevereiro de } \\
\text { 1977) }\end{array}$ & $\begin{array}{c}22,0 \text { (Janeiro de } 2013 \\
\text { e 2015) }\end{array}$ \\
\hline
\end{tabular}

Temperaturas do ar médias anuais das médias, máximas e mínimas.

As Figuras 08, 09 e 10, mostram as médias anuais das temperaturas do ar, médias, máximas e mínimas, para as Normais Climatológicas e Provisórias para Belém do Pará e observamos uma variabilidade interanual, caracterizado por um movimento cíclico ao longo do período, com uma tendência de aumento nas temperaturas do ar. A Figura 08 mostra que, a temperatura média anual foi de $25,9{ }^{\circ} \mathrm{C}$ para a Normal de 1941 a 1970 , de $26,1^{\circ} \mathrm{C}$ para a Normal de 1971 a 2000 e de $27,0{ }^{\circ} \mathrm{C}$ para a Normal Provisória, mostrando aumento nas temperaturas médias do ar, onde a Normal de 1971-2000 e a Normal Provisória de 2001-2015 apresentaram uma elevação de $0,2^{\circ} \mathrm{C}$ e de $1,1^{\circ} \mathrm{C}$ nas médias anuais, em relação ao período da Normal de 19411970 e um aumento de $0,9{ }^{\circ} \mathrm{C}$ na Normal Provisória em relação a Normal Climatológica de 1971 a 2000.
A Figura 09 mostra as temperaturas do ar médias máximas anuais para as Normais, onde as temperaturas médias máximas anuais foram de $31,5^{\circ} \mathrm{C}$, de $31,5^{\circ} \mathrm{C}$ e de $32,4^{\circ} \mathrm{C}$, respectivamente, mostrando elevação nas temperaturas médias máximas do ar, onde as Normais Climatológicas de 1941-1971 e a de 1971-2000, quando comparadas entre si, não apresentam aumentos relevantes, enquanto que, a Normal Provisória de 2001-2015 apresenta uma elevação de $0,9^{\circ} \mathrm{C}$ na média anual, em relação as Normais climatológicas.

A Figura 10 mostra a temperatura média mínima anual das Normais estudadas, onde as temperaturas médias mínimas anuais foram de $22,5^{\circ} \mathrm{C}, 22,3^{\circ} \mathrm{C}$ e de $23,1^{\circ} \mathrm{C}$, respectivamente, mostrando pequena elevação nos valores médios anuais, com $0,2^{\circ} \mathrm{C}$ mais elevada na Normal de 1941-1970 quando comparada a Normal de 19712000, enquanto que, a Normal de 2001-2015, apresentou aumento de $0,6^{\circ} \mathrm{C}$ e $0,8^{\circ} \mathrm{C}$, quando 
comparado aos valores das Normais Climatológicas de 1941-1971 e a 1971-2000.

As temperaturas médias anuais apresentaram dispersão em torno das médias climatológicas, onde para as temperaturas médias anuais, o desvio-padrão (DP) foi de $0,26^{\circ} \mathrm{C}$, $0,42^{\circ} \mathrm{C}$ e $0,27^{\circ} \mathrm{C}$ e coeficiente de variação (CV) de $1,0 \%, 1,6 \%$ e 1,0\%; para a temperatura média máxima anual, a dispersão foi de, DP de $0,49^{\circ} \mathrm{C}$, $0,48^{\circ} \mathrm{C}$ e $0,38^{\circ} \mathrm{C}$ e $\mathrm{CV}$ de $1,6 \%, 1,5 \%$ e $1,2 \%$ e para a temperatura média mínima anual a dispersão foi de, DP de $0,30^{\circ} \mathrm{C}, 0,64^{\circ} \mathrm{C}$ e $0,31^{\circ} \mathrm{C}$ e o CV foi de $1,3 \%, 2,9 \%$ e $1,3 \%$, respectivamente, mostrando que a Normal Climatológica de 1971 a 2000, foi a que apresentou maior dispersão em torno das médias climatológicas, nos valores das temperaturas médias, máximas e mínimas.

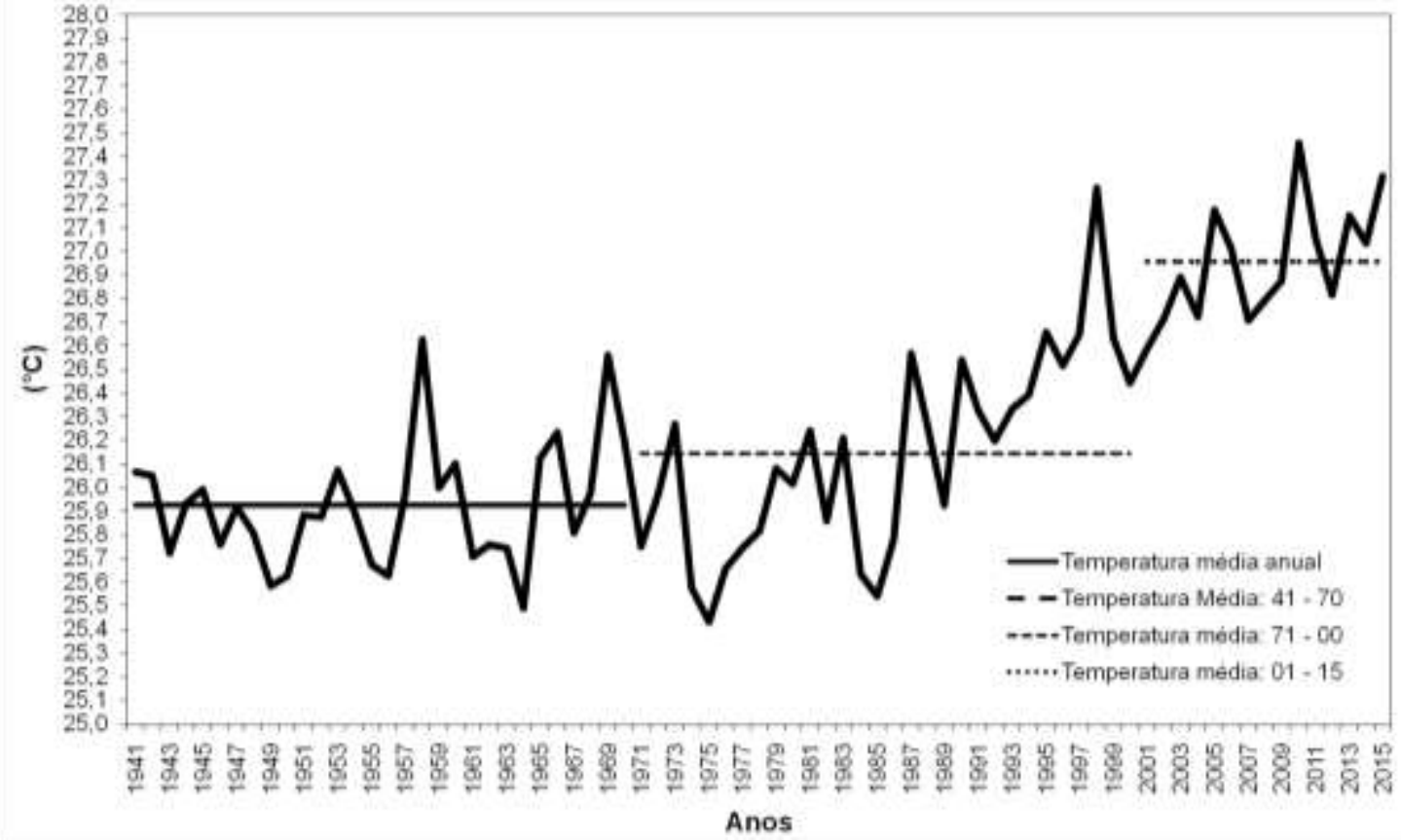

Figura 8 - Temperaturas do Ar Médias Anuais das Normais Climatológicas, 1941-1970 e 1971-2000 e Normal Provisória, 2001-2015, para Belém-PA.

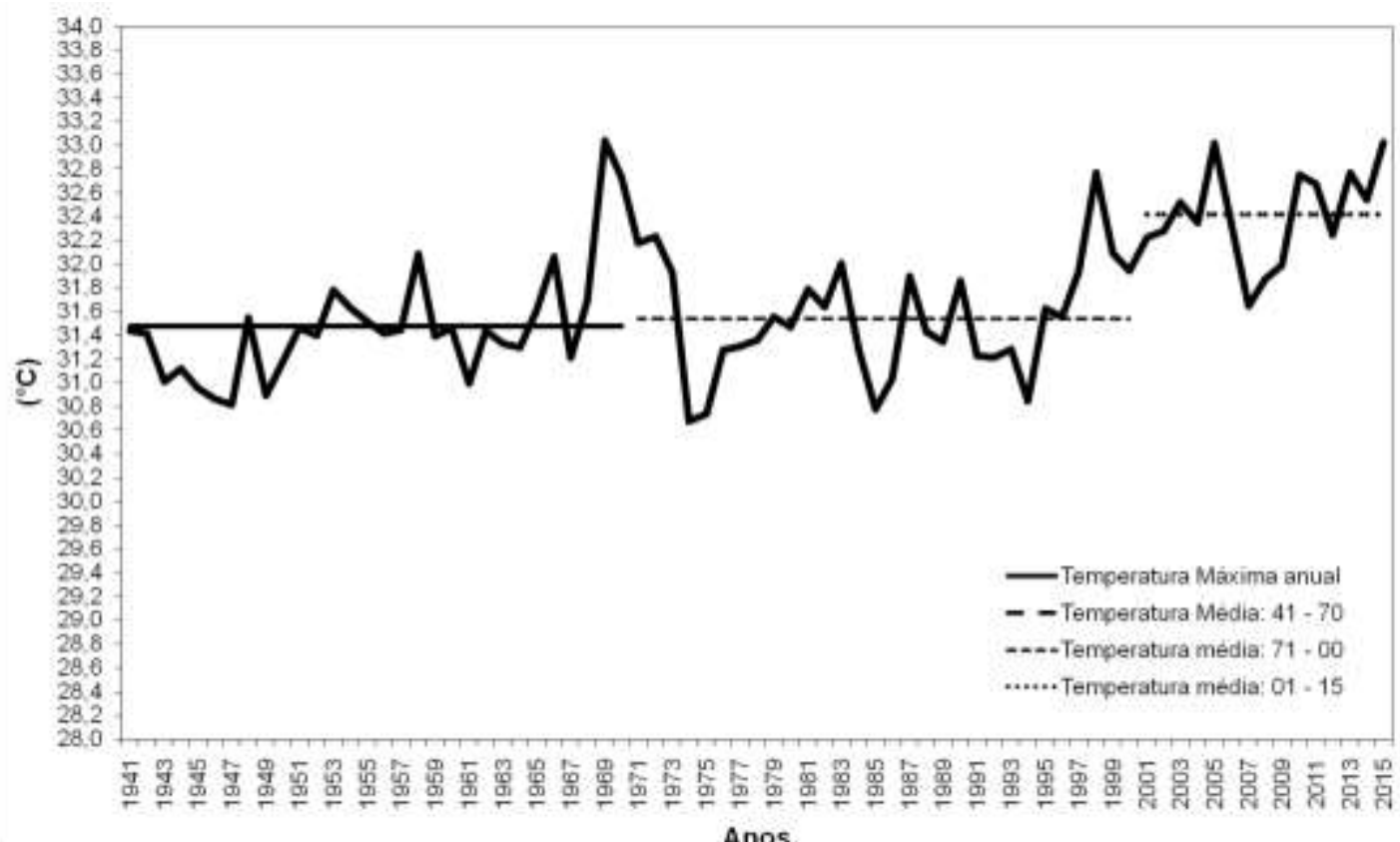

Figura 9 - Temperaturas do Ar Médias Máximas Anuais das Normais Climatológicas, 1941-1970 e 1971-2000 e Normal Provisória, 2001-2015, para Belém-PA. 


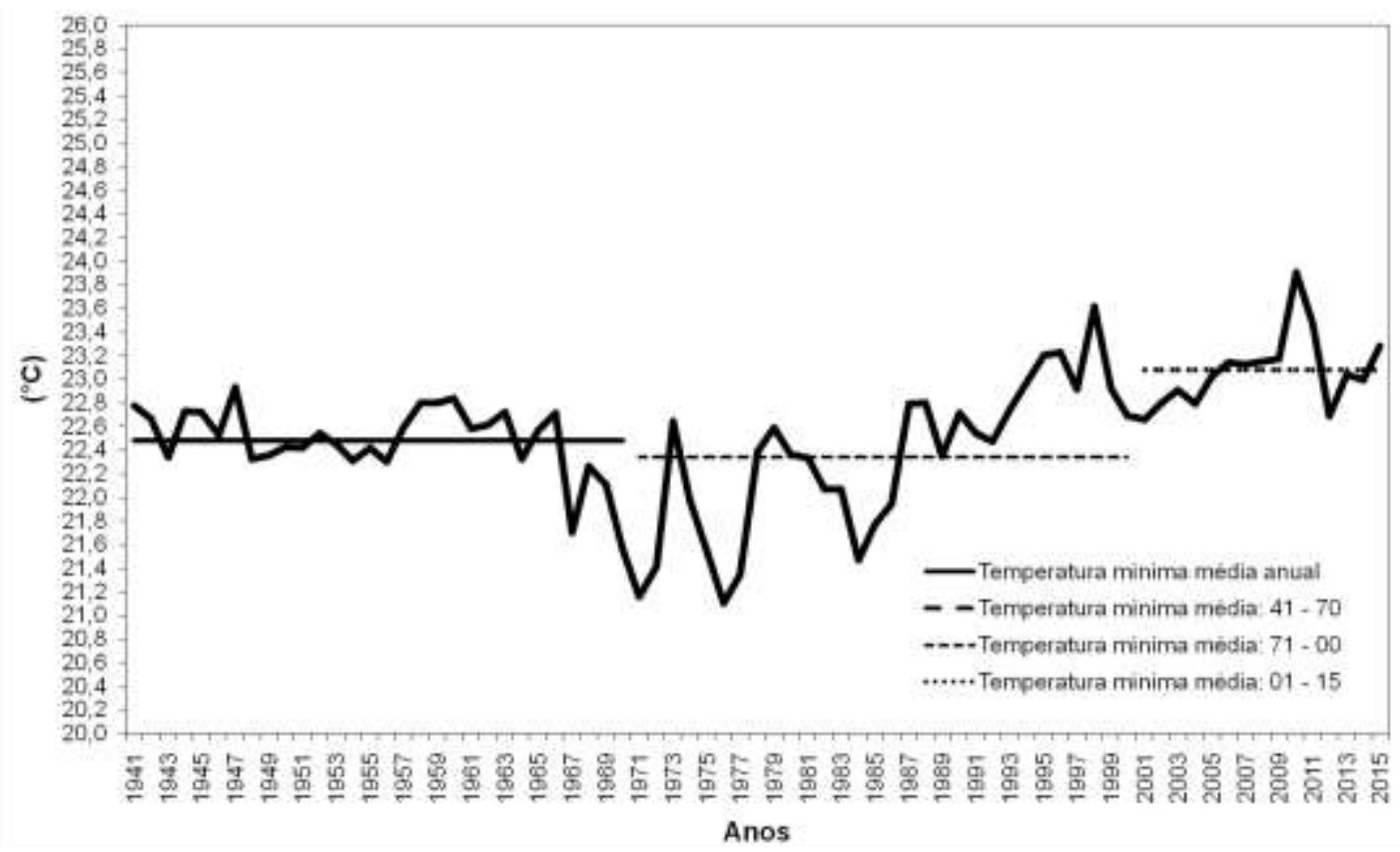

Figura 10 - Temperaturas do Ar Médias Mínimas Anuais das Normais Climatológicas, 1941-1970 e 1971-2000 e Normal Provisória, 2001-2015, para Belém-PA.

Valores extremos anuais de temperatura do ar, com os anos de ocorrência:

No Quadro 03, são mostrados os valores extremos das temperaturas do ar, médias, máximas e mínimas anuais e anos de ocorrências, das Normais Climatológicas e Normais Provisórias, para Belém-PA. O ano de 1958 foi o mais quente com valores máximos de temperatura média do ar de $26,6^{\circ} \mathrm{C}$, o ano de $1998 \mathrm{com} 27,3^{\circ} \mathrm{C}$ e o ano de $2010 \mathrm{com} 27,5^{\circ} \mathrm{C}$, respectivamente, enquanto que, os anos menos quentes foram 1964 com $25,5^{\circ} \mathrm{C}, 1975$ com $25,4{ }^{\circ} \mathrm{C}$ e 2001 com $26,6^{\circ} \mathrm{C}$, respectivamente. Os valores máximos para as temperaturas médias máximas anuais foram de $33,0^{\circ} \mathrm{C}$ em 1969 , de $32,7^{\circ} \mathrm{C}$ em 1998 e de $33,0^{\circ} \mathrm{C}$ em 2015 e os valores mínimos foram de $30,8^{\circ} \mathrm{C}$ em 1947 , de $30,7^{\circ} \mathrm{C}$ em 1974 e de $31,7^{\circ} \mathrm{C}$ em 2007, para as Normais Climatológicas e Provisórias, respectivamente. Os valores extremos máximos, para as temperaturas médias mínimas anuais foram de $23,0^{\circ} \mathrm{C}$ no ano 1947 , de $23,6^{\circ} \mathrm{C}$ no ano 1998 e de $23,9^{\circ} \mathrm{C}$ no ano de 2010 , enquanto que, os valores extremos mínimos foram de $21,6^{\circ} \mathrm{C}$ em $1970,21,1^{\circ} \mathrm{C}$ em 1975 e de $22,6^{\circ} \mathrm{C}$ em 2001, para as respectivas Normais estudadas. Os eventos fortes de El Niño de 1947, 1958, 1969, 1997, 1998, 2010 e 2015 influenciaram no aumento da temperatura do ar, como observado nos anos mais quentes, bem como, os eventos fortes de La Niña, que influenciaram na diminuição da temperatura do ar, nos anos de 1964, 1970, 1974, 1975, 1976, 2001 e 2007, nos valores das Normais estudadas, porém não podem ser desprezados outros fatores de escala global e os efeitos locais.

Anomalias anuais das temperaturas do ar, médias, máximas e mínimas em relações as médias climatológicas de cada uma das normais estudadas.

As Figuras 11, 12 e 13, mostram os valores das anomalias (positivas e negativas) das temperaturas médias anuais, média, máxima e mínima, para cada uma das Normais em relação a sua média climatológica. A Figura 11 mostra as anomalias da temperatura média anual e observase que, para as Normais de 1941-1970, 19712000, e 2001-2015, os anos de 1958, 1998 e 2010, a temperatura do ar média anual apresentou valores acima das médias climatológicas, de $0,7^{\circ} \mathrm{C}$, de $1,1^{\circ} \mathrm{C}$ e de $0,5^{\circ} \mathrm{C}$; e os anos de 1964 , 1975 e 2001, apresentaram valores abaixo de $0,4^{\circ} \mathrm{C}, \quad-0,7^{\circ} \mathrm{C}$ e $-0,4^{\circ} \mathrm{C}, \quad$ respectivamente, mostrando que, tanto o El Niño quanto a La Niña, influenciaram, nos valores das temperaturas médias anuais quando comparadas as respectivas médias climatológicas, para a região de estudo. 
Quadro 3 - Valores Extremos Anuais de Temperatura do Ar, Média, Máxima e Mínima, e os anos de ocorrência, para as Normais Climatológicas e Provisórias, Belém-PA.

\begin{tabular}{|c|c|c|c|}
\hline \multicolumn{5}{|c|}{ Temperatura Média do $\operatorname{Ar}\left({ }^{\circ} \mathrm{C}\right)$} \\
\hline & $1941-1970$ & $1971-2000$ & $2001-2015$ \\
\hline Média Anual & 25,9 & 26,1 & 27,0 \\
\hline Valor MáximoAnual & $26,6(1958)$ & $27,3(1998)$ & $27,5(2010)$ \\
\hline Valor Mínimo Anual & $25,5(1964)$ & $25,4(1975)$ & $26,6(2001)$ \\
\hline \multicolumn{4}{|c|}{ Temperatura Média Máxima $\left({ }^{\circ} \mathrm{C}\right)$} \\
\hline \multicolumn{5}{|c|}{$1941-1970$} & $1971-2000$ & $2001-2015$ \\
\hline Média Anual & 31,5 & 31,5 & 32,4 \\
\hline Valor MáximoAnual & $33,0(1969)$ & $32,7(1998)$ & $33,0(2015)$ \\
\hline Valor Mínimo Anual & $30,8(1947)$ & $30,7(1974)$ & $31,7(2007)$ \\
\hline \multicolumn{5}{|c|}{ Temperatura Média Mínima $\left({ }^{\circ} \mathrm{C}\right)$} \\
\hline \multicolumn{5}{|c|}{$1941-1970$} & $1971-2000$ & $2001-2015$ \\
\hline Média Anual & 22,5 & 22,3 & 23,1 \\
\hline Valor Máximo Anual & $23,0(1947)$ & $23,6(1998)$ & $23,9(2010)$ \\
\hline Valor Mínimo Anual & $21,6(1970)$ & $21,1(1975)$ & $22,6(2001)$ \\
\hline
\end{tabular}

A Figura 12 mostra as anomalias das temperaturas do ar médias máximas anuais e observa-se que, os anos de 1969, 1998 e 2015 apresentaram os maiores valores de anomalia positiva, com $1,6^{\circ} \mathrm{C}$ e $1,2^{\circ} \mathrm{C} ; 0,6^{\circ} \mathrm{C}$ e os anos de 1947, 1974 e 2007, apresentaram valores de anomalias negativas de $-0,7^{\circ} \mathrm{C},-0,9^{\circ} \mathrm{C}$ e $-0,8^{\circ} \mathrm{C}$, respectivamente, mostrando a influência dos eventos climáticos extremos de El Niño e La Niña, na região.

A Figura 13 mostra as anomalias das temperaturas do ar médias mínimas anuais e observamos que, as maiores anomalias positivas ocorreram nos anos 1947, 1998 e 2010 com valores de $0,5^{\circ} \mathrm{C}, 1,3^{\circ} \mathrm{C}$ e $0,8^{\circ} \mathrm{C}$ e de anomalias negativas, nos anos de 1970, 1971, 1976, $2001 \mathrm{e}$ 2012, com valores de $-1,0^{\circ} \mathrm{C},-1,2^{\circ} \mathrm{C}$ e $-0,4^{\circ} \mathrm{C}$, respectivamente, e estes anos estavam sob as influências de eventos fortes El Niño e da $\mathrm{La}$ Niña, respectivamente. Os estudos das anomalias mostraram que, os eventos fortes de El Niño influenciaram no aumento das temperaturas médias anuais, médias, máximas e mínimas, bem como, os eventos fortes da La Niña, influenciam na diminuição das temperaturas do ar, na região de estudo. 


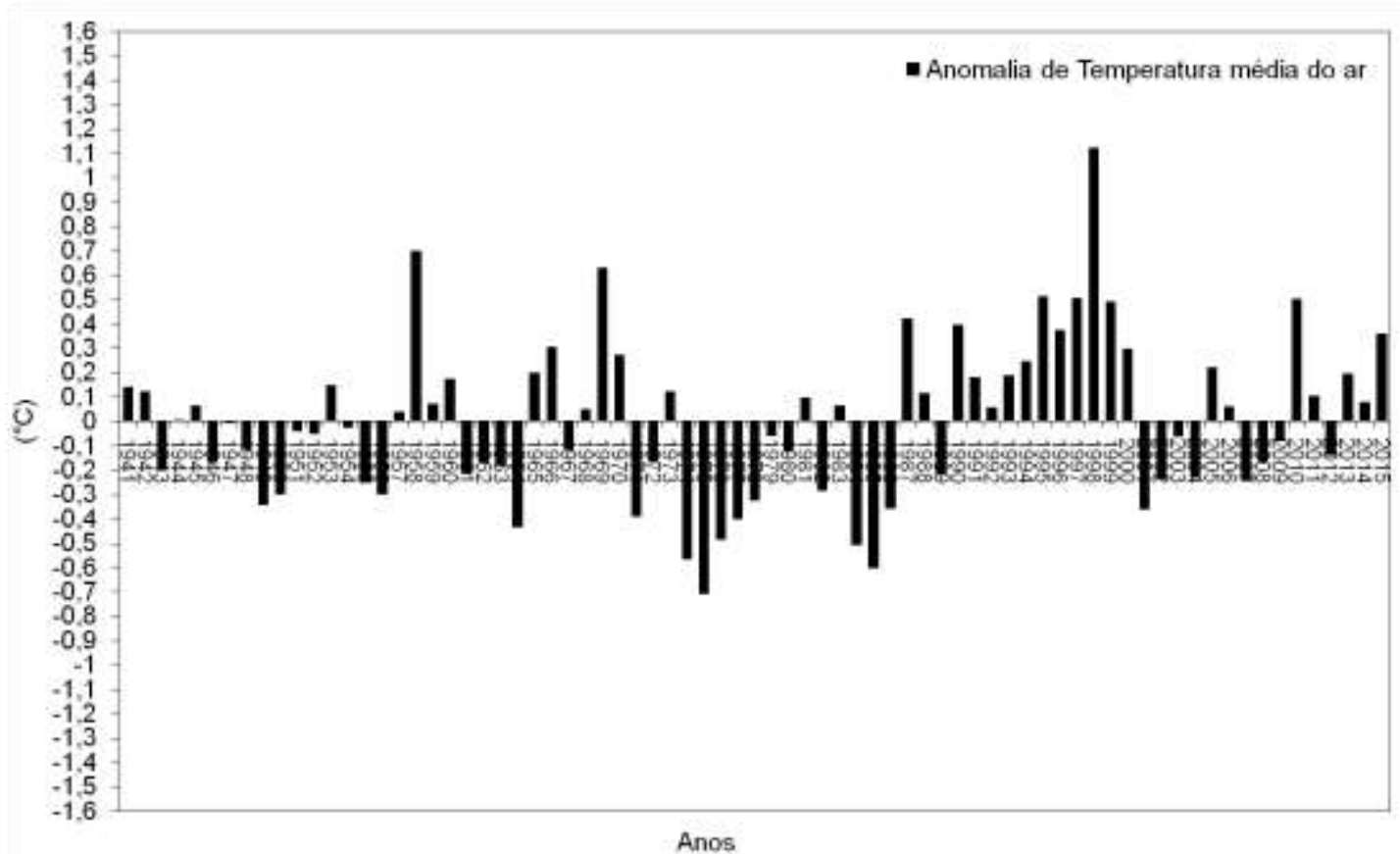

Figura 11 - Anomalias das temperaturas médias do ar, para as Normais Climatológicas, 1941-1970, 1971-2000 e Normal Provisória 2001-2015, para Belém-Pa.

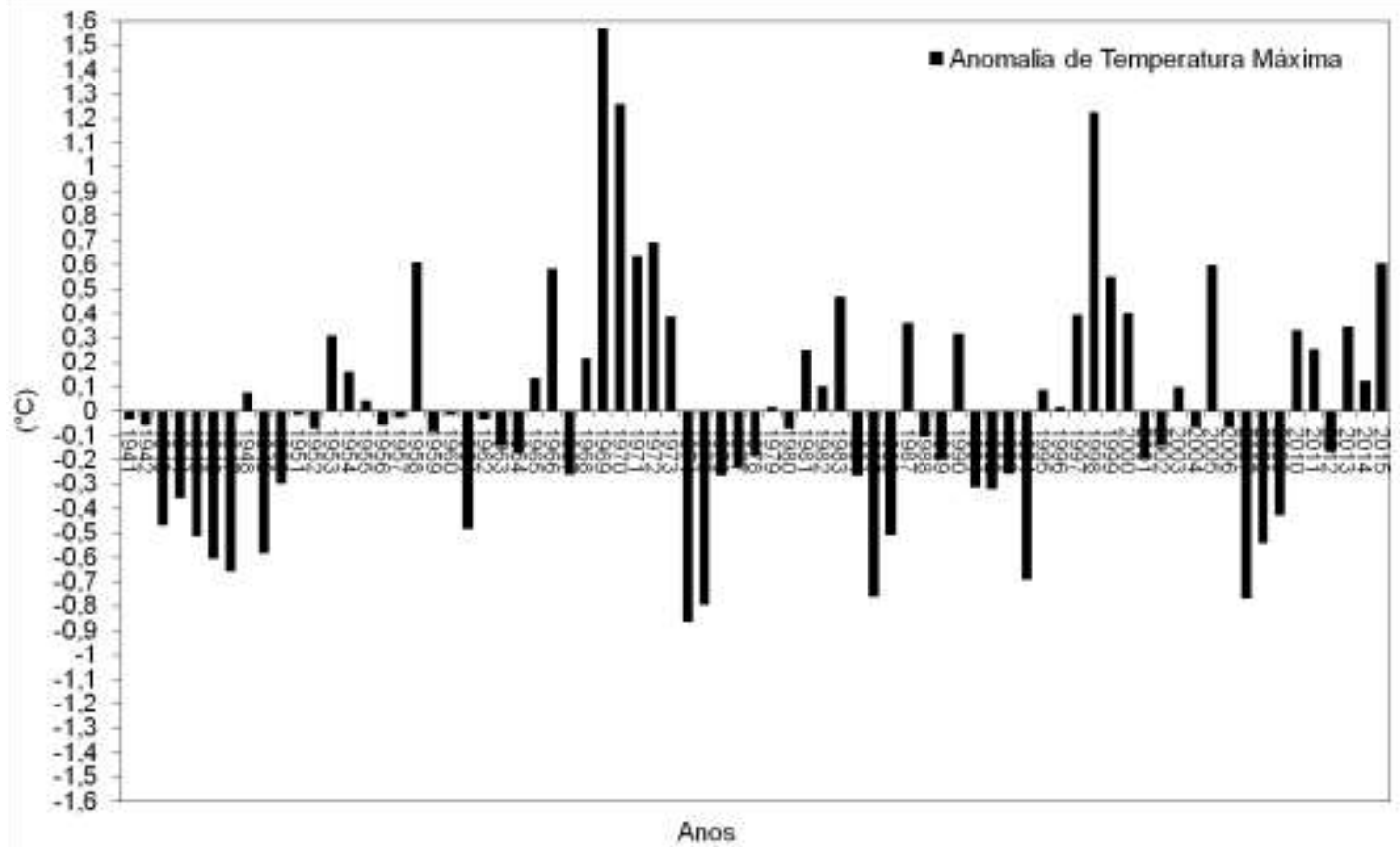

Figura 12 - Anomalias das temperaturas médias máximas do ar, para as Normais Climatológicas, 1941-1970, 19712000 e Normal Provisória 2001-2015, para Belém-Pa. 


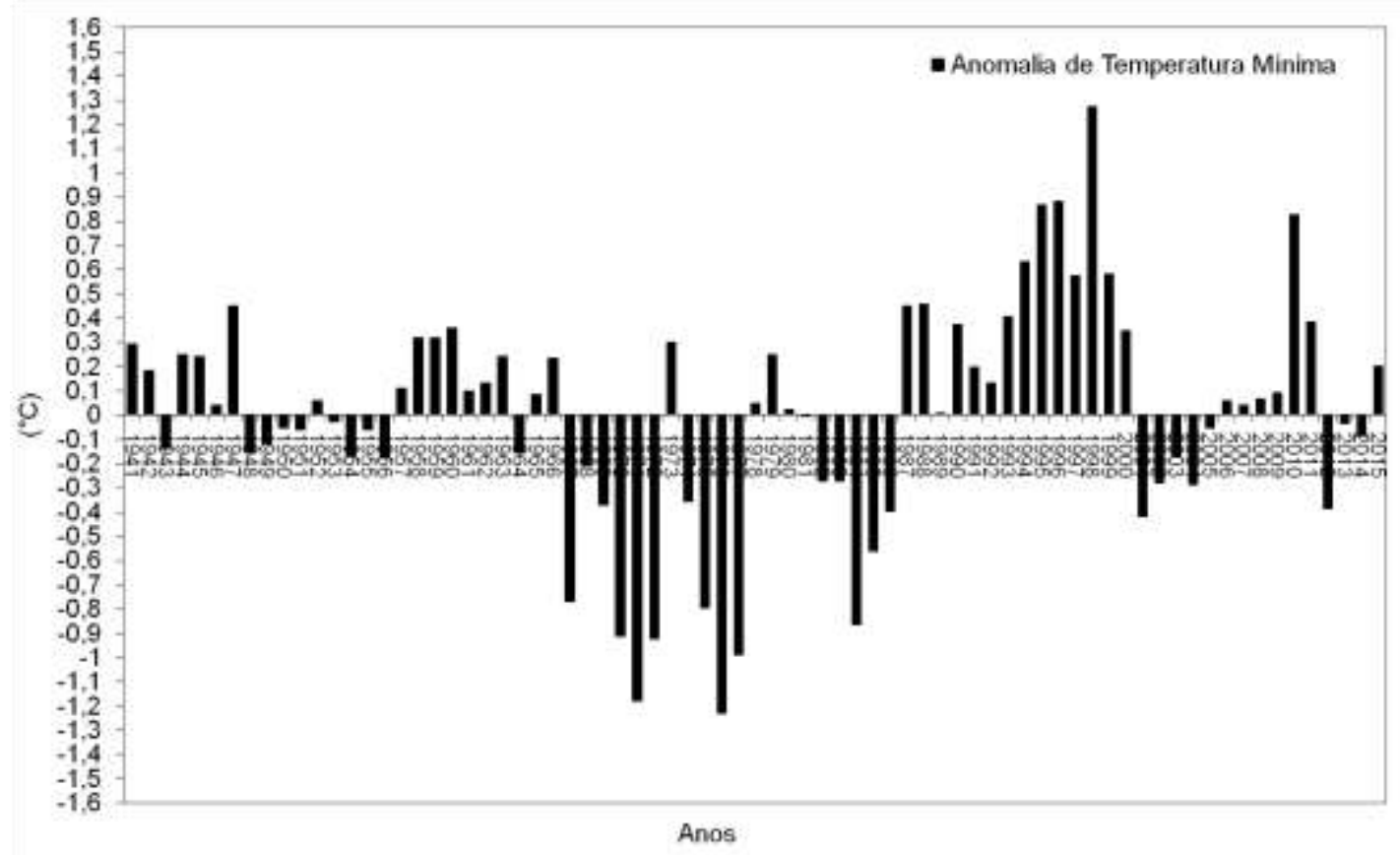

Figura 13 - Anomalias das temperaturas médias mínimas do ar, para as Normais Climatológicas, 1941-1970, 1971-2000 e Normal Provisória 2001-2015, para Belém.

\section{Conclusões}

O clima urbano em Belém-PA, através dos valores das precipitações e temperaturas do ar, das Normais Climatológicas de 1941-1970 e 1971-2000 e da Normal Provisória de 2001-2015, mostraram que, os regimes pluviométricos médios mensais apresentaram dois períodos distintos, um período mais chuvoso, de janeiro a maio e um período menos chuvoso de junho a dezembro. $\mathrm{O}$ mês mais chuvoso é março com $417 \mathrm{~mm}, 437 \mathrm{~mm}$, e $506 \mathrm{~mm}$ para as Normais e o mês menos chuvoso é novembro com $95 \mathrm{~mm}, 98 \mathrm{~mm}$, e $120 \mathrm{~mm}$, respectivamente.

$\mathrm{Na}$ comparação entre os valores de precipitação pluviométrica das Normais Climatológicas e Normal Provisória, é possível verificar aumento nos totais anuais de chuvas, aumento de 9,9\%, na Normal de 1971-2000, e de 25,2\% na Normal Provisória 2001-2015, quando comparado com a Normal de 1941-1970, e aumento de 13,95\% na Normal Provisória, quando comparado com a Normal de 1971-2000. Os valores das precipitações apresentaram variabilidade em torno da média climatológica, com valores de $9 \%$ a $13 \%$, em relação ao coeficiente de variação, e anomalias positivas e negativas, com valores extremos desde $700 \mathrm{~mm}$ em 1947 a -700 mm em 1983, estando associados aos eventos de La Niña e do El Niño. Os aumentos de chuvas na região podem estar sendo causado por fatores de grande escala, como ITCZ e eventos climáticos extremos como El Niño e La Niña, que ocorreram nos períodos estudados; por fatores de mesoescala como as Linhas de Instabilidade formadas no Nordeste do estado, e que entram na região e por fatores de microescala, como os efeitos locais e crescimento urbano desordenado, provocando aquecimento da superfície, e a formação de nuvens na região.

$\mathrm{O}$ regime de temperatura média do ar mostrou que os meses menos quentes são fevereiro e março, enquanto que, os meses mais quentes são outubro e novembro. A temperatura média anual foi de $25,9^{\circ} \mathrm{C}, 26,1^{\circ} \mathrm{C}$ e $27,0^{\circ} \mathrm{C}$, respectivamente, mostrando aumento nas temperaturas médias do ar. A temperatura média máxima mensal apresentou comportamento semelhante a temperatura média do ar, com médias mensais de $31,5^{\circ} \mathrm{C}$ para ambas as Normais Climatológicas e $32,4^{\circ} \mathrm{C}$ para a Normal Provisória. A temperatura média mínima mensal apresentou pequenas variações durante os meses do ano, com médias de $22,5^{\circ} \mathrm{C}, 22,4{ }^{\circ} \mathrm{C}$ e $23,1^{\circ} \mathrm{C}$, respectivamente. 
As médias anuais de temperaturas do ar para as Normais Climatológicas e Provisórias para Belém do Pará apresentaram uma variabilidade interanual, caracterizado por um movimento cíclico ao longo do período, com uma tendência de aumento nas temperaturas do ar médias mensais e anuais. Nos cálculos de desvio-padrão e coeficiente de variação, para as temperaturas do ar, observou-se pequena variabilidade, com valores de $1 \%$ a $3 \%$ de variabilidade em relação ao coeficiente de variação. Nos cálculos das anomalias anuais, que mostram, o quanto cada ano se afastou das médias climatológicas, observamos valores positivos e negativos nas temperaturas do ar, com valores desde $1,1^{\circ} \mathrm{C} \mathrm{e} \mathrm{-}$ $0,7^{\circ} \mathrm{C}$ (temperatura média), $1,6^{\circ} \mathrm{C}$ e $-0,9^{\circ} \mathrm{C}$ (temperatura máxima) e de $1,3^{\circ} \mathrm{C}$ e $-1,2^{\circ} \mathrm{C}$ (temperatura mínima), estando relacionados aos eventos de El Niño e La Niña de maior intensidade.

Em anos de El Niño devido à combinação entre aquecimento anormal do Oceano Pacífico conjugado com o enfraquecimento dos ventos Alísios na Região Equatorial provocando mudanças nos padrões de chuvas em Regiões

\section{Referências}

Cohen, J. C. P., 1989. Um estudo observacional de linhas de instabilidade na Amazônia. Tese (Mestrado). INPE. São José dos Campos, SP. pp.153.

Fisch, G.; Marengo, J. ; Nobre, C. A., 1996. Clima da Amazônia, Climanálise Especial. MCT/INPE/CPTEC, Cachoeira Paulista, SP, pp. 24-41.

Krusche, N.; Saraiva, J. M. B., 2001. Normais climáticas provisórias de 1991 a 2000 para Rio Grande. Rio Grande, Ed. FURG.

Lombardo, M. A. A., 1985. Ilha de calor nas Metrópolis. O exemplo de São Paulo. SP, Ed. Hucitic.

Marengo, j. E. ; Uvo, c., 1996. Variabilidade e Mudanças Climáticas no Brasil e América do Sul, Climanálise Especial.
Tropicais, provoca secas moderadas e intensas no Norte e Nordeste da Amazônia, enquanto que, a ocorrência do fenômeno La Niña, apresenta configuração inversa, com intensificação no regime de precipitação, como observado com os resultados obtidos, no entanto, alguns meses e anos apresentaram valores acima das médias das Normais e outros meses e anos abaixo das médias das Normais, tanto nos anos de El Niño como nos anos de La Niña. Os aumentos dos dias de chuvas também podem ser justificados, porque os grandes centros urbanos, devido o desmatamento e a expansão do crescimento urbano desordenado, se tornam mais quentes e isso causa aumento de temperatura do ar, podendo causar tempestades cada vez mais severas e na época menos chuvosa, essas tempestades são mais severas com rajadas de vento, pancadas de chuvas de curta duração, raios e eventualmente granizo. Finalmente que, estudos sobre o clima urbano nas grandes cidades, contribuem para um melhor planejamento urbano, visando dar subsídios as políticas públicas, com vista a melhoria nas condições ambientais, sociais, econômicas e na melhor qualidade de vida do ser humano.

MCT/INPE/CPTEC, Cachoeira Paulista, SP, pp. 1-7.

Nasrallad, H. A.; Brazell, A. J.; Balling, R. C., 1990. Analysis of Kuwait city urban heat island. International Journal of Climatology 10.

Souza Júnior, J. A., 2008. Estudo da Temperatura nos Períodos Chuvosos e Menos Chuvosos no Aeroporto de Belém-PA, em anos de LA Niña. TCC (Graduação em Meteorologia), FAMET, IG, UFPA, pp.47.

Stulppnagel, A.; Hobert, M.; Sukopp, H., 1990. The importance of vegetation for the urban climate. Urb and Ecology, pp. 175-193. 